Considerations of an idea of inhabiting reflective spaces in the hypermodern world

PALABRAS CLAVE - HABITAR · CULTURA HIPERMODERNIDAD · EDUCACIÓN · UNIVERSIDAD

KEYWORDS • INHABIT · CULTURE. HYPERMODERNITY EDUCATION - UNIVERSITY

\section{RESUMEN}

En esta investigación se busca reconocer algunos elementos fundamentales del fenómeno de la pérdida de sentido como parte sustancial de la sociedad hipermoderna, y algunas de sus consecuencias a nivel de habitar en los seres humanos, para luego establecer una relación con el contexto educativo y la formación cultural en ambientes universitarios. Situados ya en este escenario, se proponen algunas directrices que faciliten el estudio de bases teóricas iniciales, a tener en consideración al momento de proponer respuestas a los desafíos que plantean los procesos de enseñanza y aprendizaje en la educación superior, y su relación con la sociedad de la información y los medios digitales.

\section{ABSTRACT}

This paper seeks to recognize some fundamental elements of the phenomenon of loss of meaning as a substantial part of hypermodern society, and some of its consequences referred to as the inhabiting dimension of human beings, to then establish a relationship with the educational context and cultural education in university environments. Already in this scenario, some guidelines are proposed to facilitate the study of initial theoretical bases to be taken into consideration when proposing answers to the challenges posed by the teaching and learning processes in higher education and their relationship with information society and digital media.

\title{
Consideraciones sobre una idea de habitar espacios reflexivos bajo el mundo hipermoderno*
}

\author{
LIC. OMAR DAZA RUZ ·Santiago, Chile·omar.daza@ug.uchile.cl
}

Actualmente, vivimos en un contexto de crisis. No es extraño que la misma sea enunciada bajo diferentes formas, en diversos contextos, y a partir de contrastados puntos de vista. Explicar este fenómeno requiere de varias acciones importantes. Una de las primeras, responde a reconocer qué elementos nos han sido legados a partir de transformaciones de largo alcance, y cuáles corresponderían más propiamente a nuestro actual devenir. Esta tarea, inabarcable en un trabajo de mayor amplitud al presente, puede sin embargo resumirse en base a los elementos que dieran un inicio coherente a esta problemática.

Desde siempre, la formación cultural de individuos se ha generado conforme a la riqueza y unicidad de cada lugar y momento histórico: "desde antes de su nacimiento, el ser humano está ya situado con referencia a la historia que cuenta su ambiente y con respecto a la cual tendrá posteriormente que conducirse" (Lyotard, 1999, pp. 37-38). Heidegger, en su ensayo "Construir, Habitar, Pensar" (1994), publicado por vez primera el año 1951, relaciona esta visión sobre el ser humano reconociéndolo adyacente a la producción espacial de su contexto. Sus ideas resultan de vital importancia ya que, al establecer un vínculo inmanente entre pensamiento y habitar, surge la relación entre educación y arquitectura. Bajo su postura, podemos entender que distintas formas de entender el mundo, generan diferentes contextos culturales, que a su vez, originan sus propios modos de habitar el espacio.

De acuerdo a las ideas del filósofo, adquiere sentido hablar de una crisis del habitar cuando los seres humanos pierden (perdemos) este vínculo, expresado bajo formas de ocupar el espacio deshumanizadas (y deshumanizantes). Al respecto, una idea plena del habitar solo es posible desde un proceso de reflexión adecuado, convergente hacia un camino de construcción de sentido. Antonio Fernández de Alba resulta categórico: "[...] tanto nos condenan o redimen los lugares que habitamos que llegamos a ser los espacios que construimos" (2006, p. 1). Entonces, los lugares que habita actualmente el individuo constituyen una razón fundamental en la resultante de una condena, expresada como una pérdida progresiva de humanidad y libertad.

El mundo de hoy, convulso y enrevesado como nunca antes, da indicativos de un escenario general de pérdida de sentido. Respecto de las ideas heideggerianas expuestas, podemos

* Artículo realizado a partir de los resultados del seminario de investigación "Crisis del habitar en el contexto de los espacios contemporáneos de enseñanza universitaria: sociedad de la información, individuo y comunidad" realizado por el autor durante el semestre de primavera de 2017 en la Facultad de Arquitectura y Urbanismo de la Universidad de Chile (Profesora guía: Alicia Campos Gajardo) 
reconocer los caracteres globales de la crisis del habitar del presente. Según Baudrillard, el individuo, en su libre albedrío, en lugar de satisfacer su deseo de libertad, se encuentra en un estado de angustia y falta de sentido, como en ninguna época anterior (Baudrillard, 2000; Han, 2012; Lipovetsky \& Charles, 2004). La desvinculación del pensar con el habitar torna problemática una noción auténtica de libertad, haciendo evidente la noción de crisis. ByungChul Han plantea esta problemática a partir de la noción de lo híper: "la híper-información y la híper-comunicación dan testimonio de la falta de verdad, incluso de la falta de ser. Más información, más comunicación no elimina la fundamental imprecisión de todo. Más bien la agrava" (Han, 2013a, p. 23). En su diagnóstico, Han reconoce la importancia del prefijo hiperpara designar una explosión y difusión masiva de informaciones e imágenes, en un todo carente de sentido lógico. La hipermodernidad implica una sobreexageración de los hábitos y costumbres de la sociedad moderna, entendidas como las prácticas de la sociedad de consumo en función del mercado y los medios de comunicación de masas (Lipovetsky \& Charles, 2004).

Concebir una idea concreta de habitar auténtico, requiere situarse más allá de las lógicas de la hipermodernidad. Esto ya que lo híper-, anulando la convergencia de espacios de reflexión, cohíbe una auténtica libertad, entendida como el desarrollo del pensamiento sin obstáculos. Para entender esto en plenitud, es necesario consignar la facultad de contemplación de un individuo como parte sustancial de la integridad de su ser, de su autoconocimiento y de su sentido. Han expone el fondo filosófico de este propósito:

Los logros culturales de la Humanidad, a los que pertenece la filosofía, se deben a una atención profunda y contemplativa. La cultura requiere un entorno en el que sea posible una atención profunda. Esta es reemplazada progresivamente por una atención completamente distinta, la hiperatención. (2012, p. 35).
Estas ideas generan una relación profunda entre libertad y cultura. Un sentido auténtico de libertad solamente resulta factible mientras un individuo adquiera las herramientas intelectuales y humanas que le permitan vivir de manera genuina, y no solo de regirse según las lógicas impuestas en su contexto determinado.

Este análisis trae consigo a la figura de la Universidad, lugar que involucra en su sentido la construcción cultural de las sociedades. Al respecto, José Ortega y Gasset, en su ensayo, Misión de la Universidad (2001), publicado por primera vez en 1930, establece que la enseñanza ofrecida en la educación superior consiste fundamentalmente en tres postulados principales:

1. Transmisión de la cultura.

2. Enseñanza de las profesiones.

3. Investigación científica y educación de nuevos hombres de ciencia. (2001, p. 14).

Como se puede ver, el punto 1 constituye una función separable de las dos que le siguen. Por lo tanto, no se encuentra contenido en ellas. De ahí que un profesional altamente calificado puede llegar a ser un sujeto desprovisto de un sentido auténtico de formación cultural. Ortega y Gasset lo expone de modo contundente: "[el] nuevo bárbaro es principalmente el profesional, más sabio que nunca, pero más inculto también -el ingeniero, el médico, el abogado, el científico" (2001, p. 4).

La idea de cultura aquí consignada proviene del pensamiento de Nietzsche (1989), quien la define como una profunda comprensión intelectual y reflexiva de y sobre el mundo. En su argumentación, establece una diferencia frente a la versión utilitaria del rol cultural de las universidades de su tiempo (focalizadas únicamente en profesionalizar e investigar), situadas en una sociedad ajena al pensamiento. Resulta evidente cómo esta noción utilitaria se ha agudizado en la sociedad de la información.

Ortega y Gasset, sin embargo, asumiendo el pragmatismo de las instituciones de educación superior, propone organizar a la enseñanza universitaria desde el estudiante, no del profesor ni del saber. Hoy, esta visión viene a representar parte importante de la ideología educativa, a través de la cual los nuevos medios informáticos se han integrado a los mecanismos de enseñanza y aprendizaje. Muy al contrario de la defensa que realiza Nietzsche (1989) a la sujeción del estudiante a los grandes maestros, como parte necesaria en la formación. Según el autor, la ausencia de un guía experimentado conduce a la vaguedad y la indecisión, conllevando, como consecuencia, a lo que entendió en sus propios términos como pérdida de sentido.

Hoy se defiende una idea de educación vinculada a la libre circulación de cómputos y datos, que ha llevado al individuo ha encontrarse inmerso en un mar de informaciones. Sin embargo, el desarrollo educativo requiere de una idea de detenimiento, por tanto, la producción intelectual en contextos comunitarios no debiera obstaculizarse en mérito a la rapidez de la vida hipermoderna.

Resulta evidente que esta idea no ha sido abordada en la mayoría de los contextos educativos. Por el contrario, muchos teóricos de la sociedad hipertexto, han llegado a proponer una anulación de los espacios físicos, en miras a una totalización de los entornos digitales, basándose en las ideas de la "educación permanente" (Almada, 2000), esto es, que en la rapidez de la vida misma se encuentra integrado lo educativo. Jordi Adell (1997), manifiesta que esto se debe fundamentalmente al interés tecnocrático de algunos profesionales, que anteponen disciplinas de economía y procesos de mercado a lo que concierne propiamente a la educación.

Desde estas reflexiones surge una consideración esencial hacia la arquitectura, puesto que desde la misma se constituye la dimensión de actos que materializan el habitar. $Y$ desde la establecida relación con el pensar, se extrae una complejidad exponencialmente mayor a un simple estar en el mundo (Romañá, 2004), 
involucrando valencias afectivas, conocimiento y vivencias corporales, además de acuerdos sociales y culturales que producen y reproducen encuentros humanos.

De acuerdo a esto, corresponde estudiar la posibilidad de concebir lugares que pudieran dar al habitar una índole reflexiva, en virtud de constituir una respuesta al escenario totalizador de las prácticas hipermodernas. Esto ya que el escenario actual parece no dar demasiadas luces al respecto. Habermas resume así este diagnóstico: "en la fase de gran aceleración, la expansión educativa ha generado ideologías concomitantes" (1987). Resulta evidente que han habido consecuencias arquitectónicas en los establecimientos educativos derivadas de la sociedad informatizada.

En este ámbito, la rapidez de los ritmos de trabajo incide sobre el desvirtuamiento de espacios programáticamente concebidos para actividades definidas: lugares destinados a desplazamiento, por ejemplo, terminan dando cabida a espacios de permanencia, debido, entre otros aspectos, al apremio de la demanda académica. En ese sentido, la Universidad viene a expresar, en sus espacialidades, una pérdida de sentido a través de sus programas arquitectónicos, existiendo ejemplos como el casino del Campus Creativo, cuya función originaria se funde en actividades de taller y trabajo de ordenador.

Según James Steele (2001), el ordenador modifica radicalmente los modos de habitar. A nivel de ámbitos educativos formales, esto puede verse en las nuevas aulas inteligentes, que involucran conjuntamente trabajo digital y presencial.

Si algo resulta evidente, es que la Universidad Institucionalizada debe asumir los nuevos cambios de la sociedad de la información. De otra manera, solo conduciría su desmantelamiento. En este sentido, debe tomar una decisión fundamental: o reconvertir sus prácticas académicas a la absoluta virtualidad, o seguir un camino mixto, combinando esquemas de enseñanza presencial con los de la educación a distancia (Almada, 2000).

Sin embargo, conectar sus prácticas de aprendizaje con una crítica a la sociedad de la información, y otorgar a las diferentes instancias educativas un carácter de auténtica formación cultural, exige una preocupación encarecida frente a su constitución espacial, y a las formas de habitar que surjan desde ella.

Según el arquitecto Pablo Campos (201 1a), cada elemento disponible en el complejo universitario debe otorgar posibilidades de un habitar pleno y satisfactorio, lo cual puede contribuir a la tarea educativa. Esto se relaciona con lo que José María Touriñán (1998) define como procesos informales de educación, esto es, actividades que no solo no niegan la función educativa de los espacios formalizados para tales usos, sino que además, producen resultados con un alto valor de aprendizaje, a través de estímulos que pueden no representarlo de modo directo (por ejemplo, espacios destinados a actividades recreativas).

La arquitectura, buscando responder a estas interrogantes debiera, en primer término, enfatizar la importancia del encuentro de carácter físico en los espacios educativos: "la universidad [...] necesita erigir lugares corpóreos, imágenes construidas con las que el hombre que los habita pueda identificarse" (Campos, 2000, p. 221). Campos también realiza una crítica a la preponderancia de los recursos digitales en contextos educativos: "el planificador de campus Richard Dober afirmaba [...] que 'Internet transmite datos, no valores'. Las palabras del arquitecto norteamericano ponen el dedo sobre la verdadera misión de la Universidad" (2011 , p. 26). El concepto de misión inserto en esta última cita guarda una relación profunda con las ideas de Ortega y Gasset sobre lo Universitario. A partir de las ideas recogidas de este filósofo, entendemos que un modelo de educación centrado en el estudiante se origina a partir del entendimiento de lugares que posibiliten un habitar educativo.

Las ideas de Pablo Campos pueden ser tratadas reconociendo algunos conceptos generales. Varios de sus trabajos reconocen el término diversificación espacial. En lugar del programa antojadizo y desvirtuado de las universidades producto de los influjos telemáticos, este concepto aborda una intencionalidad arquitectónica que, enriqueciendo al habitar, favorece a lo educativo.

En su análisis, aparece el concepto de calle didáctica: un lugar que constituye más que un mero transitar, permitiendo el desarrollo de múltiples actividades. Una idea que la posibilite constituye, por ejemplo, la fusión de distintas tipologías urbanas, como la calle y la plaza. Estos espacios distienden del estrés y favorecen a la comunidad universitaria (Campos, 2011 ). De este modo, el detenimiento en ciertas zonas de la Universidad favorecerá un mejor rendimiento en otras actividades. Esto puede facilitarse mediante acciones tales como: aminorar el paso, situando elementos de detenimiento como nichos y mobiliario, creando lugares de pausa que disuaden de la permanente rapidez (FIGURA 1); y enaltecer las cualidades del divertimento, dando connotaciones lúdicas que brinden calidez y acogida a las experiencias informales de aprendizaje (FIGURA 2).

También su análisis arquitectónico considera a los espacios de uso personal. Esto, ya que lugares de reflexión individual o en grupos pequeños favorecen facultades de contemplación. Por lo tanto, estos espacios debieran tener su sitio en complejos universitarios. 
A nivel de comunidad, la arquitectura debe escapar de las ideas de rigidez inherentes a los esquemas educativos tradicionales. Un buen ejemplo podemos encontrarlo en el Nieuwmarkt Playground (1968), de Aldo Van Eyck, cuyo diseño permite una mayor liviandad y fluidez entre espacios, favoreciendo diferentes situaciones de aprendizaje (FIGURA 3).

En los distintos complejos de educación superior, deben existir diseños espaciales que sepan dar cabida a las necesidades humanas que van más allá de lo utilitario, ya que las complejas variables del habitar comprenden un estudio de todos los usos y desempeños que diferentes individuos requieran según sus intereses, los cuales, evidentemente, no se mantienen estáticos. Lógicamente, la arquitectura no debiera actuar por sí misma, existiendo también de modo encarecido, un diálogo permanente al interior de las universidades que contenga una crítica a la hipermodernidad siempre que esta deteriore sus fundamentos.

Para Pablo Campos, la Universidad Contemporánea enfrenta el desafío de asumir las propiedades del Campus Didáctico (Campos, 2010), modelo que será capaz de llevarla más allá de la idea de un mero contenedor material. Por el contrario, la volverá eventualmente capaz de transmitir valores y proyectar contenidos desde sus propias cualidades arquitectónicas, lugarizando una eutopía (Campos, 2010). Esto es, la concreción material de una utopía, en este caso, la auténtica idea educativa, la formación integral de seres humanos. En otras palabras, y retomando las ideas iniciales de esta investigación, puede ser vista como un camino de recuperación del sentido de la misión universitaria, cuyo idealismo pone su centro no solo en investigar y profesionalizar, sino en dar a la transmisión cultural un profundo significado a nivel de existencia y de sentido.
1. Circulación exterior Campus Didáctico, Universidad Andrés Bello. Fuente: elaboración propia.

2. "The Parabel", Facultad de Matemáticas y Ciencias Informáticas de la Technical University of Munich. Fuente: elaboración propia, basado en imagen de https://studyabroad.case.edu/).
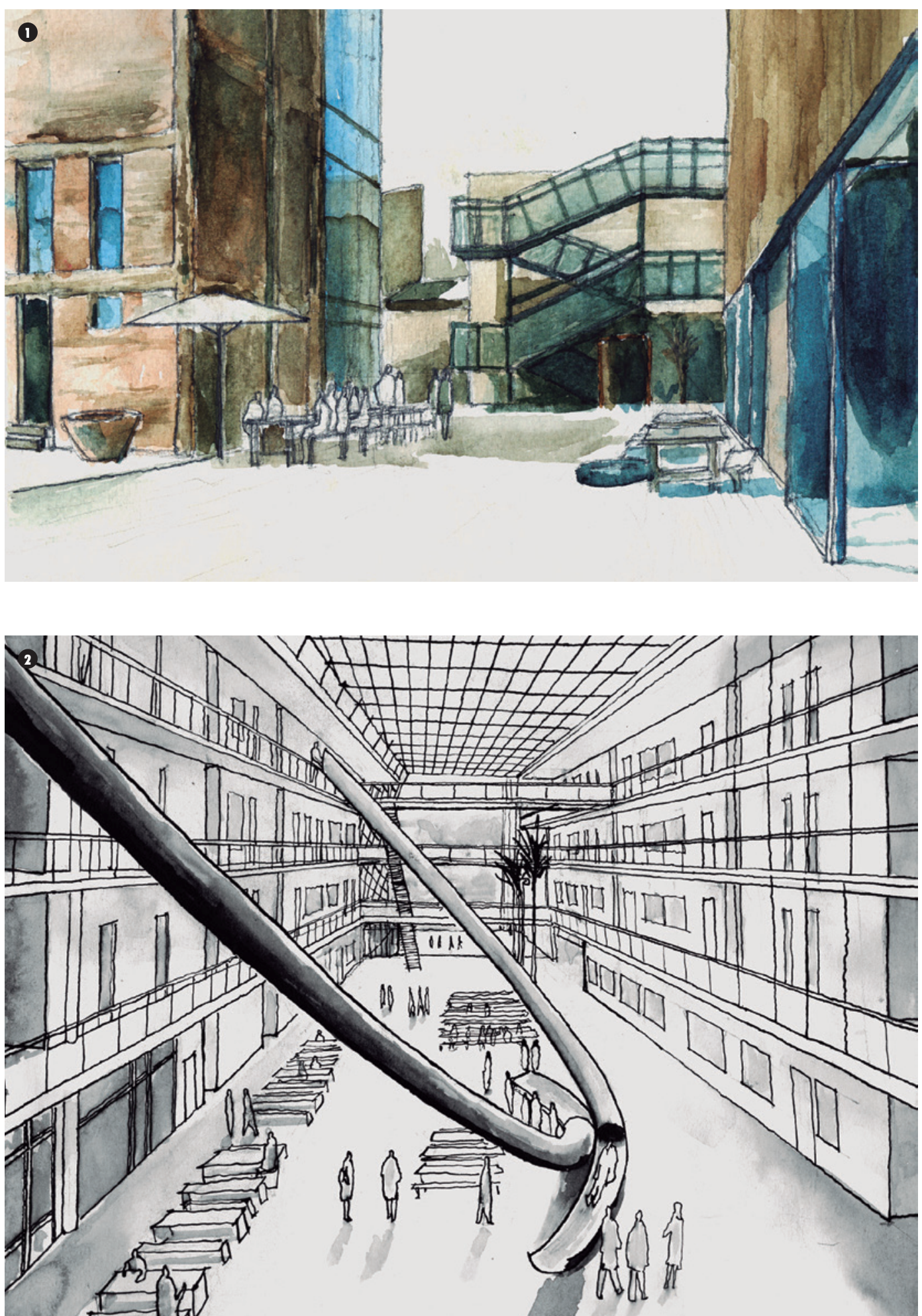
3. Nieuwmarkt Playground (1968), Van Eyck. Fuente: elaboración propia, basada en imagen de http://www.play-scapes.com/
3

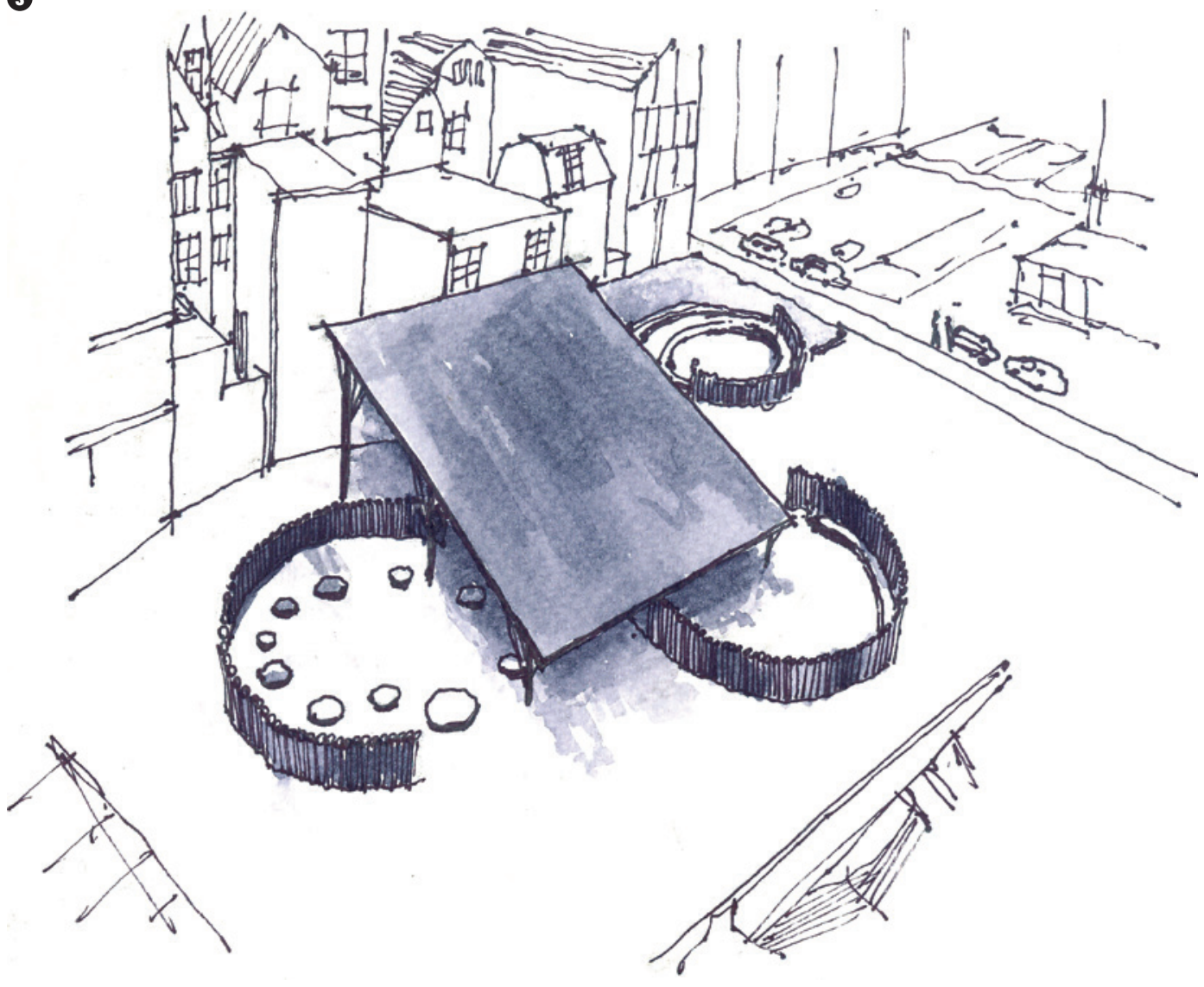

\section{REFERENCIAS BIBLIOGRÁFICAS}

Adell, J. (1997). Tendencias en educación en la sociedad de las tecnologías de la información. EDUTEC, Revista Electrónica de Tecnología Educativa, 7. https://doi.org/10.21556/ edutec. 1997.7.570

Almada, M. (2000). Sociedad multicultural de información y educación. Papel de los flujos electrónicos de información y su organización. Revista Iberoamericana de Educación, 24, 103-133. Recuperado de https://rieoei.org/RIE/ article/view/999
Baudrillard, J. (2000). Las estrategias fatales. Barcelona: Anagrama.

Campos, P. (2000). La arquitectura de la universidad. Historia de la Educación. Revista Interuniversitaria, 19, 207-224. http://revistas.usal.es/index. php/0212-0267/article/download/10788/11186

Campos, P. (2010). La arquitectura de la formación humana: el campus didáctico como Eutopía. Madrid: CEU Ediciones. Recuperado de http:// hdl.handle.net/10637/3361

Campos, P. (201 la). Espacios innovadores para la excelencia universitaria: estudio de paradigmas de optimización docente y adaptación al Espacio
Europeo de Educación. Madrid: Ministerio de Educación-Secretaría General de Universidades. Campos, P. (201 1 b). La evolución histórica del espacio físico de la universidad. Madrid: Repositorio institucional e-Archivo

Fernández de Alba, A. (2006). Palabras sobre la ciudad que nace. Madrid, España. Recuperado de https://www.coam.org/media/Default\%20Files/ fundacion/biblioteca/donativos\%20de\%20autor/ PALABRAS-SOBRE-LA-CIUDAD-QUE-NACE.PDF

Habermas, J. (1986). La idea de la universidadprocesos de aprendizaje. Explorando en la Universidad, 5. https://doi org/10.4324/9780203425817

Han, B.-C. (2012). La sociedad del cansancio. Barcelona: Herder.

Han, B.-C. (2013). La sociedad de la transparencia. Barcelona: Herder.

Heidegger, M. (1994). Construir, habitar, pensar. En E. Bariau (Trad.), Martin Heidegger, Conferencias y artículos (pp. 1-11). Madrid: Ediciones del Serbal.

Lipovetsky, G. \& Charles, S. (2004). Los tiempos hipermodernos. Barcelona: Anagrama.

Lyotard, J.-F. (1989). La condición postmoderna. Madrid: Cátedra.

Nietzsche, F. (1989). Sobre el porvenir de nuestras instituciones educativas. Barcelona: Tusquets.

Ortega y Gasset, J. (2001). Misión de la universidad. Madrid: Cátedra.

Romañá, T. (2004). Arquitectura y educación: perspectivas y dimensiones. Revista Española de Pedagogía, 62(28), 199-220. https://dialnet. unirioja.es/descarga/articulo/995398.pdf

Steele, J. (2001). Arquitectura y revolución digital. Barcelona: Gustavo Gili.

Touriñán, J. M. (1998). Compartir el mismo espacio y tiempo virtual. Una propuesta de investigación para la intervención pedagógica. Revista de Educación, 332, 213-231. Recuperado de https://dialnet.unirioja.es/servlet/ articulo? codigo $=776733$ 